\title{
Methodology for Drought Risk Assessment in Within-year Regulated Reservoir Systems. Application to the Orbigo River System (Spain)
}

\author{
David Haro • Abel Solera • Javier Paredes • \\ Joaquín Andreu
}

Received: 10 January 2014 / Accepted: 10 June 2014 /

Published online: 24 June 2014

(C) The Author(s) 2014. This article is published with open access at Springerlink.com

\begin{abstract}
Drought occurrence and its related impacts are a major concern in many river basins throughout the world. In the last years, drought management procedures have moved from a crisis approach towards a more sensitive preparedness approach. Drought plans development has arisen as an effective way of providing measures and actions to manage drought situations. However, due to each river basin has different operation characteristics, drought management requires a different approach in order to be efficient. Decision support tools are a great ally of water managers, especially in situations of high water stress and hydrologic uncertainty, allowing them to in-deep analyze the system and finding the best measures to minimize the risk of a system failure. This paper studies the difficulties of only using an indicator system based in current and past data to assess the drought risk in within-year regulated reservoir systems. It proposes the complementary use of a general risk assessment methodology to anticipate the future probable status of the system and defining the current drought scenario. It shows how the complementary use of a monitoring system and a risk assessment decision support system may improve the drought detection process allowing water managers optimizing the selection of mitigation measures and minimizing the probability of overreaction during a drought situation.
\end{abstract}

Keywords Drought. Water resources systems management - Risk assessment - Decision support system $\cdot$ Stochastic multi-scenario analysis

\section{Introduction}

In recent decades, intense drought events have been observed on all continents with high economic and social costs (Mishra and Singh 2010). Drought forecasting is still a complex task (Bordi and Sutera 2007), and intensity and duration of future droughts remain unknown until the episode has finished. Water managers confront severe uncertainties within the decision

D. Haro $(\bowtie) \cdot$ A. Solera $\cdot$ J. Paredes $\cdot$ J. Andreu

Water and Environmental Engineering Institute, Universitat Politècnica de València, Camino de Vera $\mathrm{s} / \mathrm{n}$, 46022 Valencia, Spain

e-mail: dahamon@upv.es 
making process, both in the short term (management and operation) and long term (planning), in any water resources system where droughts are very frequent and where water resources are under a massive use.

Because of the difficulty at detecting drought episodes occurrence, and forecasting their intensity and duration, the traditional responses to drought have been reactive, adapting the measures to the severity of impacts as long as they were detected in what is called a crisis management. This approach is ineffective, poorly coordinated, and untimely; and does little to reduce the risk associated with drought (Wilhite et al. 2000). Because of this, drought management has evolved in recent years towards a more risk-preventive approach. Drought planning must predict what is predictable and establish strategies of prevention and management of the growing drought risks generated within the current climate change dynamics (Arrojo 2007). To reduce drought risk, there must be an understanding of the hazard using climatology, improved operational monitoring, an analysis of vulnerability to understand what people and sectors may be most affected by drought, why these impacts occur, and if these relationships are changing over time (Hayes et al. 2004). This new risk management based approach to drought management has been expressed in the necessity of developing drought management plans (Wilhite 1996; EC 2000) that provide a dynamic framework for an ongoing set of actions to prepare for, and effectively respond to drought, including periodic reviews of the achievements and priorities; readjustments of goals, means and resources; as well as strengthening institutional arrangements, planning, and policy-making mechanisms for drought mitigation.

Drought planning requires preliminary identification and analysis of the risks associated to the occurrence of this natural phenomenon. Additionally, the mitigation measures within a drought prevention strategy need a study within the context of the system so the managers select the ones that yield best cost/effectiveness relation. To carry out these tasks, software tools efficiently integrated within a decision support system (DSS) are of great help in order to enhance the capabilities of decision makers (Rossi et al. 2006). The use of such systems allows developing and using real time management models able to assess the risk of drought, and the effectiveness of proactive and reactive measures applied on regular basis for the management of river basins (Andreu et al. 2009). DSSs also permit the monitoring of drought by evaluating the different indicators and drought indices defined for the studied river basin. Additionally, they represent a powerful tool for participatory processes since, as seen in Wilhite et al. (2000), the different stakeholders involved in drought planning have a chance to develop and understanding of one another's various points of view, and to generate collaborative solutions. A DSS is the common platform that the different stakeholders can use to show their proposals and understand how these would affect the rest of the participants. The whole modeling process especially when all the interested parties collaborate in its development helps building common knowledge and shared vision on the system.

The use of monitoring systems and calculation of drought indices and indicators help water managers defining risk scenarios. The entrance of a system in each of those scenarios will activate different measures addressed to minimize the possibilities of entering a worse scenario and minimizing the possible effects of the current situation. However, this approach may not work as well as expected in water resources systems subject to strong seasonal operation schemes such as within-year reservoir systems. In these cases, relying on the status of the system to start making decisions towards the future of the river basin may result in unnecessary over reaction.

This paper studies the problems for assessing drought risk in within-year operated river basins and how that affects the drought management process, especially due to the high seasonality. We propose complementing the common used methodology, particularized for 
within-year regulated reservoir systems, with the use of future risk results obtained by simulating the future behavior of the system in a Monte Carlo approach with multiple equiprobable streamflow series with different anticipation periods. We will show the advantages of including the real management of the system in a seasonal approach to assess drought risk under uncertain hydrology conditions instead of a month-to-month approach that does not include it. We apply the proposed method to the Orbigo River basin in Spain.

\section{Materials and Methods}

\subsection{The Orbigo River Basin (Spain)}

The Orbigo River is a tributary of Esla River at the north-west of the Iberian Peninsula, traversing the provinces of Leon and Zamora, both in the region of Castilla y Leon (Fig. 1). The total surface drained by this river is of about $5,000 \mathrm{~km}^{2}$, being its length of $162 \mathrm{~km}$. Average precipitation within the basin is of $725 \mathrm{~mm}$ per year and the average potential ETP is $755 \mathrm{~mm}$ per year. Average natural flow is $1,576 \mathrm{hm}^{3}$ per year composed approximately by surface and groundwater flow in almost the same proportion. Reservoirs in the system have a total regulation capacity circa $373.6 \mathrm{hm}^{3}$ being the two most important the Barrios de Luna and Villameca reservoirs, both at the headwaters of the system. Demands reach approximately $466 \mathrm{hm}^{3}$ per year representing irrigation demand $96.5 \%$ of it. The hydroelectricity production represents a small amount.

As can be perceived, in the case of the Orbigo River, the regulation capacity is quite lower than the amount of resources available, and even lower than the total demand of the system.

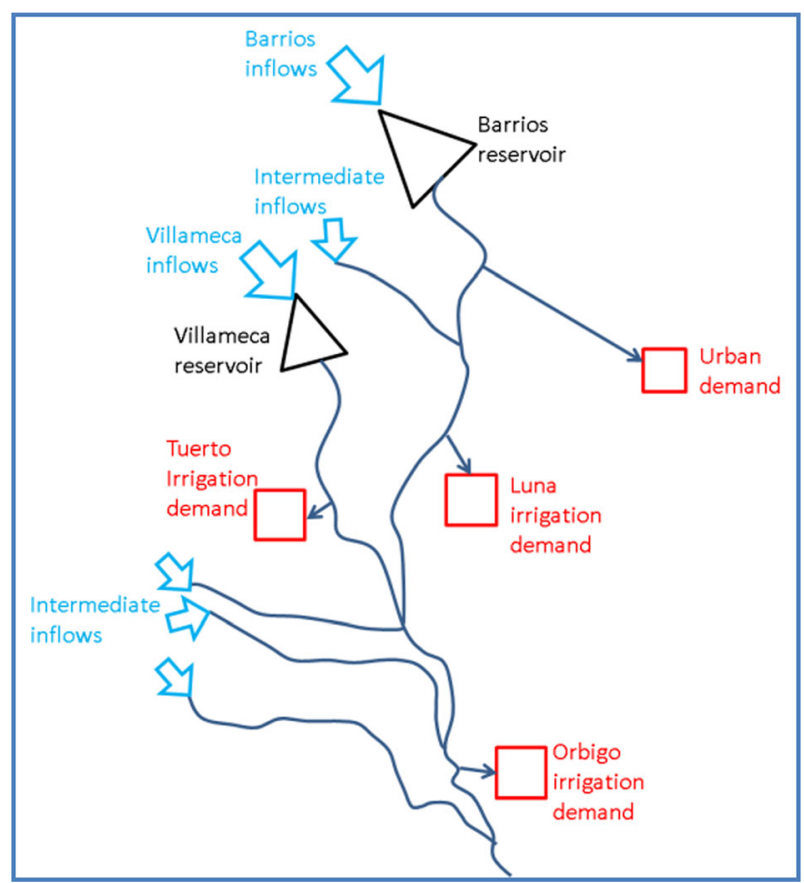

Fig. 1 Scheme view of the Orbigo River basin 
Reservoirs in the system have an important role in flood prevention and lamination during the rainy seasons in autumn and spring, as well as resource suppliers in the more dry months of summer. This makes reservoirs often are empty at the end of the summer and are full again for the irrigation season in a within-year regulation cycle. In the last times, the Orbigo River basin has suffered several dry spells. In 1988-1989, irrigation was put to a second plane to ensure urban water supply. Year 1998-1999 was an extremely dry year but a good water distribution saved the irrigation campaign. Finally, in 2001-2002, irrigation campaign had to finish in August due to a bad management of the system.

\subsection{Current Drought Monitoring and Risk Assessment Methodology}

Behavior differences of over-year and within-year regulated river basins make necessary using different points of view when approaching management and planning under normal conditions. In the same way, drought situations management should be approached differently too. Failing at detecting and determining the start of a drought episode does not have the same consequences in one kind of system or another. Within-year systems require more immediacy and accuracy because of the rapid changes within them, while over-year systems may allow some delay if conditions are not extremely bad.

The anticipation in the application of mitigation measures becomes an essential tool for the reduction of socio-economic and environmental impacts of droughts; that is why having a complete indicator system that allows calling an early alert of these extreme events and activate in advance the program of measures established for these emergency situations is crucial (Estrela and Vargas 2012). An indicator system for a river basin is formed by a series of variables that describe the basin drought status and include reservoir storages, groundwater piezometric levels, streamflows, reservoir inflows and precipitation. The different values taken by the indicator define the drought status and degree of severity. Different monitoring systems were developed worldwide in recent times. Rossi and Cancelliere (2013) and Tsakiris et al. (2013) make extensive reviews of the approaches and different methodologies for drought monitoring and risk assessment.

For the case studied, drought plans in Spain establish four different levels of drought: normality, pre-alert, alert and emergency (MMA 2007). These levels are determined according to the monitoring system established at each river basin. The monitoring system has a hydrologic character since its practical interest lays on its ability to serve as decision-making instrument regarding water resources management in the basin. For each river basin, managers select the indicators that better represent the water resources offer for the different demand units existing in the basin. These indicators must reflect the resources availability in a homogeneous way and thus, these are selected among reservoirs storage, piezometric levels, natural streamflows and areal precipitation. The drought levels in the basin are defined as the weighted sum of the State Index $\left(\mathrm{I}_{\mathrm{e}}\right)$ values of each of the selected indicators.

The value of the State Index $\left(\mathrm{I}_{\mathrm{e}}\right)$ has the following expression:

$$
\begin{aligned}
& -\quad \text { If } V_{i} \geq V_{a v} \rightarrow I_{e}=\frac{1}{2} \cdot\left[1+\frac{V_{t}-V_{a v}}{V_{\max }-V_{a v}}\right] \\
& -\quad \text { If } V_{i} \geq V_{a v} \rightarrow I_{e}=\frac{1}{2} \cdot \frac{V_{i}-V_{\min }}{V_{a v}-V_{\min }}
\end{aligned}
$$

with $\mathrm{V}_{\mathrm{i}}$ the value of the indicator in the month $\mathrm{I} ; \mathrm{V}_{\mathrm{av}}$ the average value of the indicator in the historic series considered; and $\mathrm{V}_{\max }$ and $\mathrm{V}_{\min }$ the maximum and minimum values of the indicator in the historic series considered.

The definition of the State Index considers the following criteria: 
- Arithmetic average is a robust statistic, as well as simple; so a comparison of the indicator value with the average of the historic series considered will adjust better to the real situation of the selected drought region. Although, it is necessary to take into account the maximum and the minimum historic values.

- It is necessary to homogenize indicators in a dimensionless numeric value capable of quantifying the current situation with respect to the historic, and a quantitative comparison between the different indicators selected.

The thresholds that define the different levels of the drought status of the system normally are:

- Normality (green): $\mathrm{I}_{\mathrm{e}} \geq 0.5$

- Pre-alert (yellow): $0.5>\mathrm{I}_{\mathrm{e}} \geq 0.3$

- Alert (orange): $0.3>\mathrm{I}_{\mathrm{e}} \geq 0.1$

- Emergency (red): $0.1>\mathrm{I}_{\mathrm{e}}$

For the Orbigo River basin, the state index is calculated as the weighted sum of the volume stored at the largest reservoir (Barrios de Luna, $w=0.9$ ) and the inflows to the second largest (Villameca, $w=0.1$ ) in the Orbigo River basin. Figure 2a shows the evolution of $\mathrm{I}_{\mathrm{e}}$ from October 1996 to September 2010. It is possible to observe how the drought status varies several times within the same year, going from normality to almost emergency and back. It is also easy to appreciate that most of the alert and emergency situations occur by the end of the hydrologic year, something that is logic since the operational management of this basin requires the reservoirs to be empty by that time of the year. Therefore, there is an evident difficulty at determining when such a system is in a drought situation from the value of its indicator due to the high seasonality of the system. We recalculated the State Index by using the monthly average, maximum and minimum values for each different month instead of the values of the whole time series (Fig. 2b). It is easy to appreciate that there is a clear difference between normality and drought periods while they remain at the same periods of time as detected originally (1998/99 and 2001/02). At the same time, drought periods that were less evident (2005/06 and 2007/09) now reveal as important events. Anyway, despite it is easier to discern between normality and drought periods, the change from one scenario to another still occurs very quickly to detect the development of a serious drought event in time. Therefore, in the case of systems where seasonality plays an important role in their management, it will be necessary to have additional tools to determine drought risk more accurately.

\subsection{The SIMRISK Methodology}

Following a preventive approach in drought management requires advancing, to a certain extent, the possible impacts a drought episode may have on the water resources system. To do this it is necessary both forecasting drought characteristics and assessing their effects on the system. For the first part, there are a series of methodologies that have shown their capabilities in the last years: regression, time series analysis, probability models, artificial neural networks and hybrid models. Mishra and Singh (2011) present a more detailed discussion on these techniques. With regard to the second aspect, the forecasted characteristics of future drought events can feed a decision support system that allows assessing the possible effects of future events, for example by optimizing the definition of risk indicators (Rossi et al. 2012) or assessing the vulnerability of the system (Preziosi et al. 2013). 
(a) Current methodology

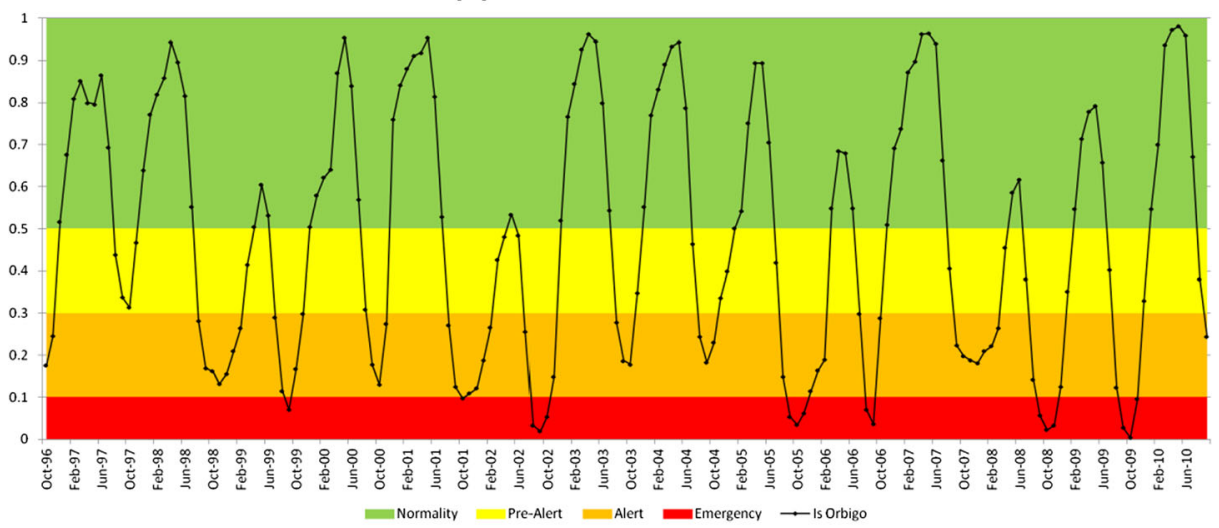

(b) Recalculated

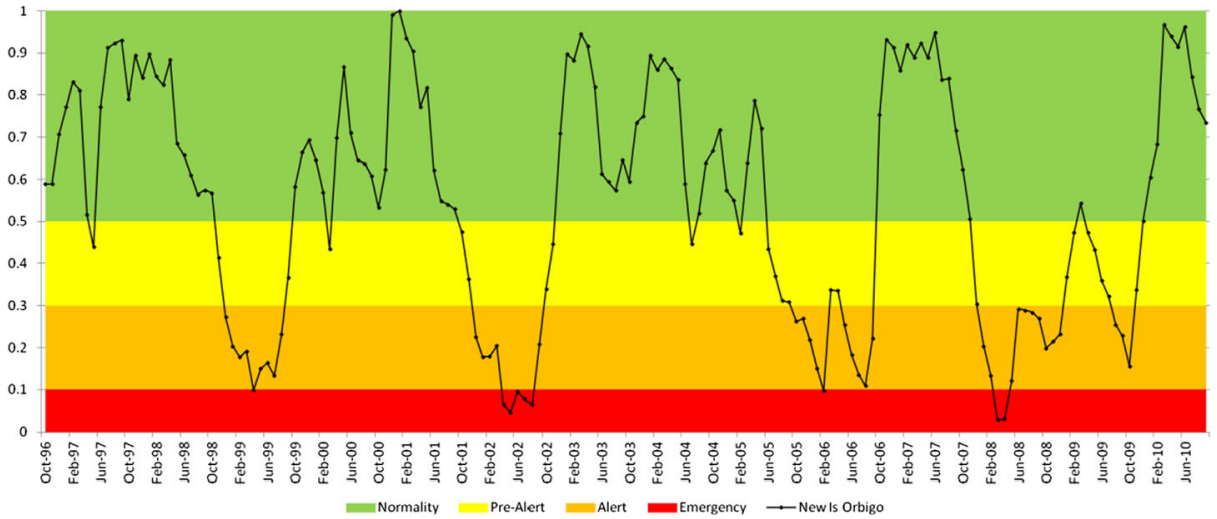

Fig. 2 State Index for Orbigo River basin for the period 1996/97 to 2009/10 calculated with the current methodology (a) or with the modified one (b)

SIMRISK is a generalist methodology that analyses the actual management of a complex water resources systems, anticipates the risk of having problems with future resources availability and allows evaluating and justifying the most appropriate mitigation measures. SIMRISK was initially developed in Sánchez-Quispe (1999) and Sánchez-Quispe et al. (2001), and it is implemented in the decision support system shell AQUATOOL (Andreu et al. 1996). Cancelliere et al. (2009) also propose a similar methodology.

The analysis process is based in the Monte-Carlo method and consists of generating multiple, future, probable, natural streamflow scenarios for a determined anticipation period, and simulating the system management for each of them according to the objectives and supply criteria decided previously. Each of the simulations will yield different results with regard to the system operation, namely supplies, shortages, reservoir withdrawals, aquifer extractions, environmental flow compliance and hydropower generation. All these results are treated statistically to obtain the risk level at which the system may be in the following months.

Figure 3 shows a scheme that summarizes the methodology in which, starting from the current situation of the system, the decision makers can obtain information about the risks 


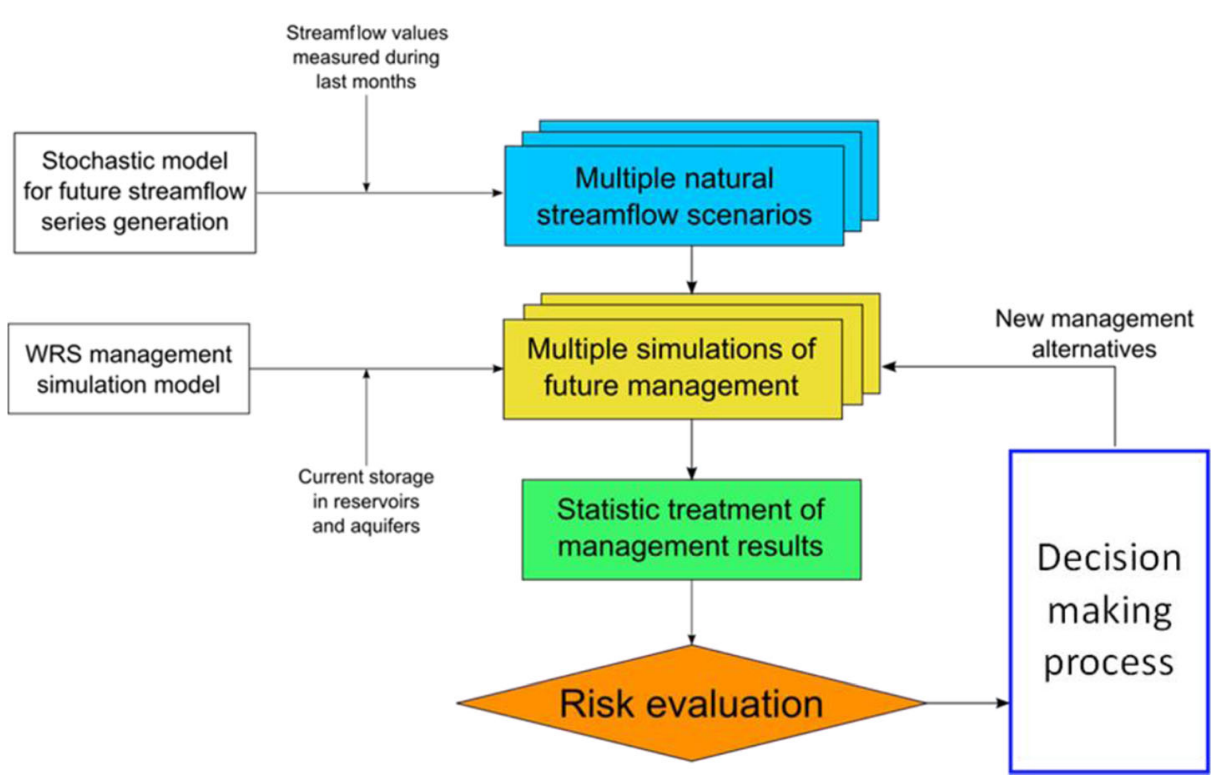

Fig. 3 Scheme of the workflow using the SIMRISK methodology

assumed for the future as a consequence of the operation of the system. If the risk level obtained by the actual management of the system cannot be assumed, management alternatives can be studied with the methodology obtaining new risk levels in an iterative process.

The methodology is an interesting tool to use with and by stakeholders during public participation processes addressed to find the best management practices for drought risk minimization as seen in Andreu et al. (2009).

\subsubsection{Water Resources System Management Simulation Model}

SIMRISK requires information about the status, objectives and a physical definition of the analysed system. The storage levels in reservoirs and aquifers, as well as recent natural streamflow measurements, define the status of the system. The objectives are the demand supplies proposed for the following campaigns (one or more, depending on the anticipation period defined) and the reliability accepted for them. Finally, a management simulation model gives the physical description. The model should be capable of representing the real operation of the system with as much detail as possible. The model selected for the implementation of the methodology is SIMGES (Andreu et al. 2007).

SIMGES allows developing simulation models of complex water resources systems in which the user can define regulation and storage elements both superficial and subterranean, water transportation elements either river reaches or manmade, consumptive or nonconsumptive demand elements, and withdrawal elements from both surface and groundwater. The model simulates water management at a monthly timescale according to user defined operation rules. Minimum environmental flows can be defined as well as different users priorities for water supply and more complex operation rules. The model calculates the monthly management by translating the system scheme to a network flow in which the solution algorithm determines the circulating flows with an objective function that minimises demands and environmental flows deficits and maximises water storage and hydroelectric production requirements. The results of the model include the evolution of all the relevant 
variables in monthly and annual level, average values for the whole simulation period as well as the reliability of supply.

\subsubsection{Stochastic Model for Future Streamflow Series Generation}

Using SIMRISK requires a high number of streamflow series that are equiprobable with the historic one. It is thus necessary calibrating and validating some kind of stochastic model from which is possible to generate as many synthetic series as necessary to carry out the analysis process. For the case study of the Orbigo River basin, an autoregressive model of first order, $\mathrm{AR}(1)$, resulted enough to generate series that preserved the statistic characteristics of the historic series.

We generate series under a conditioned basis, utilizing as initial values the observed streamflows in the months prior to the generation of the synthetic series. The length of the synthetic series will depend, again, on the characteristics of the river basin modeled. However, since conditioned generated series tend to become homogeneous after a certain amount of generations, the most interesting length to analyze will normally be either one or two campaigns in one run. Anyway, the methodology is developed to be used as a complement of the drought monitoring system existing at the basin. Thus, generation of series should be done once a month. In addition, revising the stochastic models to adapt them to possible hydrologic changes is a task that should be done every few years.

\subsubsection{Statistic Treatment of Management Results}

The model aggregates the results of the Monte-Carlo simulations of the system with the several generated synthetic series. This aggregation provides probability distributions for reservoirs storage; shortages at consumptive demands; aquifers extractions; and status of drought monitoring indicators. Managers can use these results assess the risk of the basin to be in a drought situation given the current management and the possible effects it would have on the system. This will help the decision makers drawing the different alternatives of management to minimize possible impacts. With this methodology, it is also possible to analyze new management alternatives or mitigation measures to select the most effective ones at reducing the risk.

\subsubsection{Application to Within-year Operated Systems (Case of the Orbigo River)}

As seen before, the use of monthly updated state index as a mean to detect developing drought episodes in water resources systems with a high seasonality is not completely effective for the means of preventive management. In first place, because it is not possible to compare storage values in reservoirs from 1 month to another due to the quick fluctuations introduced by the system operation. Normally, the storage levels at the beginning of the irrigation campaign, right after spring rainy season, will have nothing to do with the values at the beginning of autumn, in which reservoirs are usually empty both because of the use of stored water for supply during summer and as flood prevention. Second, the historic data to calculate the state index in reservoirs is very heterogeneous since they contain the variation in time of infrastructures and demands. These conditions are very likely to change in the future. Finally, the risk in within-year systems is mainly determined by the inflows to reservoirs during the winter and spring seasons. Since the summer and autumn are periods in which reservoirs normally keep low storage levels because of operational and protection issues, the failure in the system will be more likely to happen if there have been a series of dry months during the winter and spring, 
that are the months in which water is stored. Therefore, a low state index during the months in which the system is supposed to present low storage levels is not representative for the risk assessment in future months.

Given the limitations of defining the risk of drought in within-year operated system with an indicators system, the risk assessment methodology presented above results an excellent complement to the drought management process. It contains the current situation of demands and infrastructures together with recent data of storage levels and hydrological inflows. This means that all the information, processed separately in the calculation of the system state index, is considered together and it is also possible to include updated information regarding near future management information, while the indicator assumes that management is always going to be similar to the previous one. The results obtained are a straightforward lecture of possible future results that, in the end, is what matters to water managers and allows them to make decisions. The risk assessment methodology perfectly integrates the high seasonality of data since the multiple simulations contain that same variability. However, a long-term prediction will always be less reliable than a short-term one, although results evaluation can consider this fact when necessary.

Regarding the definition of the drought scenario existing in the water resources system, current drought indicator systems measure the severity of future drought with regard the conditions in the date of observation. However, this measured severity is going to be different if the observation is done in winter (before the rain season and after the irrigation one), than if it is done by the end of spring or the beginning of summer (the chances of future precipitation are low and the need of water is high). If we do a risk calculation for the coming summer during the previous autumn in a within-year operated system such as the Orbigo River, the risk perception will be low. This is due to the probability that a month with high precipitation occurs and changes the whole prediction. Under this assumption, we cannot classify a failure forecast with an anticipation period higher than 6 months as an emergency, but maybe as an alert. Consequently, drought scenarios definition should be according to two factors: risk of failure and anticipation period.

In order to show the usefulness of the SIMRISK methodology regarding drought risk anticipation and effectiveness of measures, we analyzed 24 different scenarios. The scenarios are a combination of initial month of simulations (October, January, April and July); initial storage levels at the basin reservoirs (low and medium); and previous hydrologic conditions (average, dry and minimum). Average hydrologic conditions use as initial streamflows the average streamflow calculated from the historic series; dry conditions correspond to half of previous average conditions; and minimum conditions use as initial inflow the lowest record in the historic series. Each of the scenarios contains 10,000 different synthetic series that span for three consecutive campaigns. The reason to simulate such amount of series is capturing in the probabilistic results all, or the most, of their variability.

\section{Results and Discussion}

Regarding the efficiency of the monitoring system, Fig. 4 shows, for the scenario starting October with low reservoir levels and average hydrologic conditions, the evolution of the system State Index along the three campaigns simulated with the SIMRISK calculated with the complete historic series values as the drought plan proposes (a) and with the alternative monthto-month calculation method (b). Each of the lines corresponds to the values of the state index with a certain probability of non-exceedance. In this way, the lighter blue lines represent the state index values evolution that were not be exceeded the $99 \%$ of the times in the 10000 
simulations, and so on until the darker blue line that represents the $10 \%$ probability of nonexceedance. From Fig. $4 \mathrm{a}$, it is possible to observe that the indicator system proposed by the drought plan does not really allow anticipating whether there is a risk of suffering a drought situation since, during the months before the beginning of the irrigation campaign (May), most of the probabilities fall under the normality scenario. Additionally, during the irrigation campaign the state index value drops very quick and makes that the end of the campaign appears to be always in a severe risk of drought. Since within-year systems normally end the hydrologic year with low reservoir levels, an indicator system that takes into account all the values of the historic series will always show an important risk of being in a drought situation. However, if the possible values of the state index are calculated by comparing the indicator values obtained only with the values corresponding to that particular month (Fig. 4b), it is possible to obtain a better probability distribution in which one can observe that there is a possibility to be in a risk situation even though the storage levels are high. This points out the fact that low state index values do not necessarily mean a high risk of a prolonged drought situation in all cases, especially in within-year operated systems, but there is a need for improved monitoring systems. We can also appreciate from the graph that the longer the simulation period is, the more homogeneous are the results. This is due to the tendency to homogeneity of the synthetic series used, and is a characteristic of ARMA models. This makes this methodology a very interesting tool to analyze systems especially up to one year or one year and a half in advance, which are the time periods normally considered in management.

\section{Probable State Index value evolution}

(a) Complete time series values

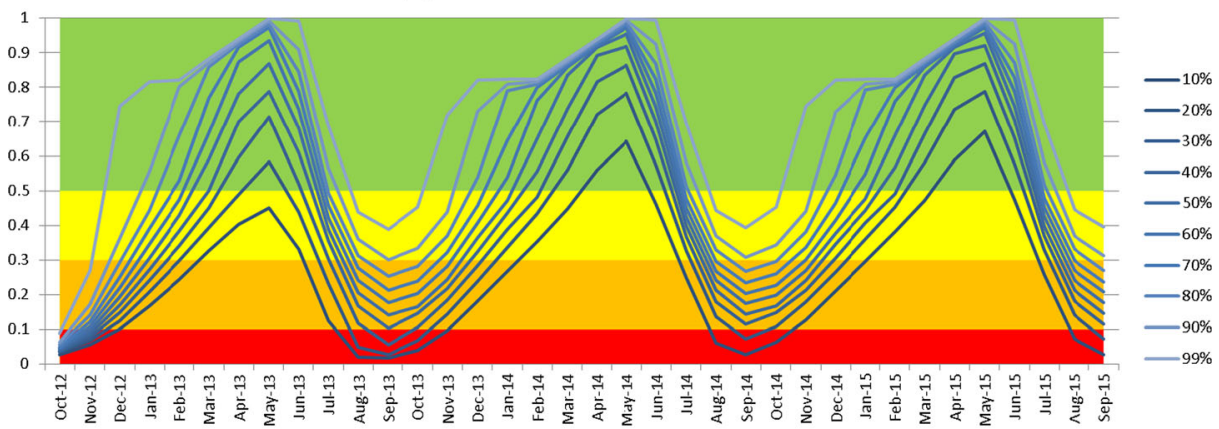

(b) Month-to-month time series values

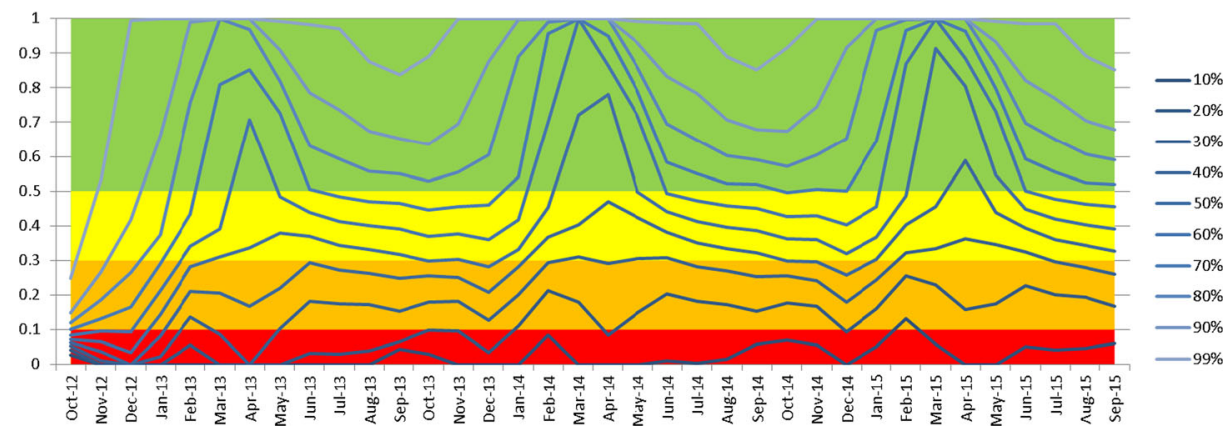

Fig. 4 State Index evolution along the three campaigns calculated with the whole time series values (a) and with month-to-month values (b) 
Unlike the indicators system, that supplies a single state index value according to the current conditions, SIMRISK provides a probability distribution of the state index value several months in advance. Therefore, the definition of the current drought scenario combining both approaches requires a more detailed analysis. As stated in the previous section, we must take into account both risk level and anticipation period to define the drought scenario when using the SIMRISK methodology. In first place, there will normally be a level of risk, below which the system managers will not want to be. This level either can be determined from the analysis of historic situation or agreed between all the stakeholders of the system, although it will usually be a mix of both by means of participatory processes. As an initial rule of thumb, the historic distribution at the end of the campaign is a good indicator of what is normal in the system. All the graphs in Fig. 5 incorporate that historic distribution for comparison with the risk assessment results. The moment of the year selected to analyze the risk situation is the end of the hydrologic year, which coincides with the end of the irrigation campaign. Normally, a situation of normality at this stage will mean that the campaign ended without supply problems. Values below normality will show that there were from minor to larger problems during the previous months. In the case of the Orbigo River basin, it is possible to observe that historic operation of the system has resulted in situations at the end of the campaign below normality the $65 \%$ of the times, below pre-alert the $36 \%$ of the times, and below alert, thus in emergency situation, the $13.5 \%$ of the times. On average, the system usually has reached the end of the hydrologic year in a situation of pre-alert (a value of the state index of 0.4 for the $50 \%$ probability). We can consider a good thing that the risk assessment shows an average risk level within the limits of the pre-alert scenario at the end of the campaign. If the average risk level is above, it will represent a very good situation and, if it is below it will be necessary to consider a change in the drought scenario.

On the other hand, we can also consider the anticipation period as a very important factor for the definition of drought scenarios in the system. On this regard, the graphs in Fig. 5 show the possible status of the basin by the end of the first campaign from four different anticipation periods. As discussed in the previous section, assessing the risk level at the beginning of the

(a) End of first campaign 12 months

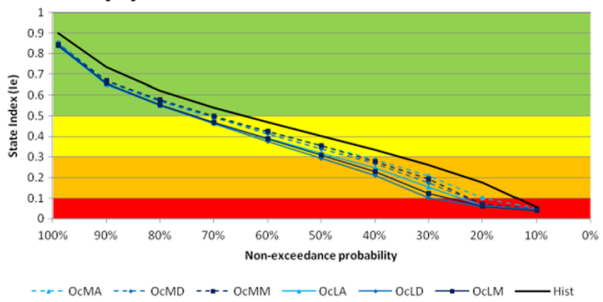

(b) End of first campaign 9months

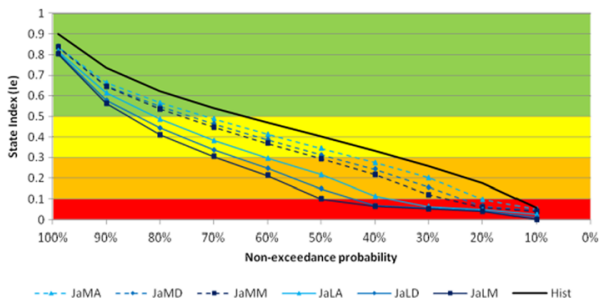

(c) End of first campaign 6 months

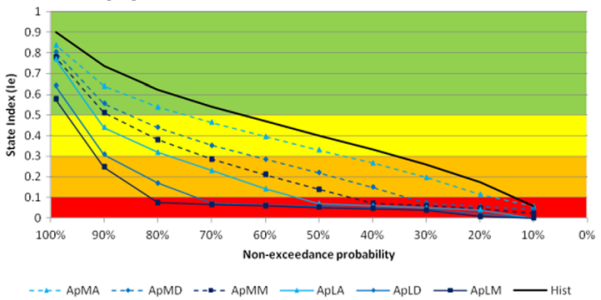

(d) End of first campaign 3 months

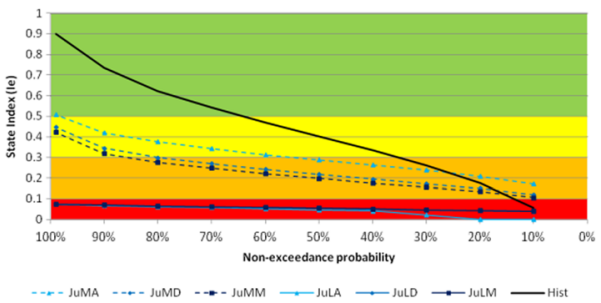

Fig. 5 Probability distributions of state index values at the end of the first campaign (September) for four different anticipation periods 
hydrologic year does not really allow deriving whether there is a real risk of suffering a severe drought situation. Figure 5a shows that all the scenarios almost match each other and the historic distribution despite initial storage levels and previous hydrological conditions and, in all cases, the $50 \%$ probability risk level falls within the pre-alert scenario boundaries. When observing figure $5 \mathrm{~b}$, for an anticipation period of 9 months, it is already possible to think that there may be some issues by the end of the campaign. However, at that particular moment, only the autumn rains have occurred and it is still possible that spring precipitations change the results. In the case of an anticipation period of 6 months, Fig. $5 \mathrm{c}$, there are little possibilities of additional inflows to the basin until the end of the campaign but there will be a drastically increase of water use from that moment. The resulting risk levels are already a good measure of the possible situation of the basin at the end of the campaign. It is possible to see that only in the case of medium storage levels and average previous hydrologic conditions the risk is within acceptable levels. This may alert water managers to start taking actions to bring the risk level back to acceptable values with enough time for these measures to be effective. Finally, Fig. $5 \mathrm{~d}$ shows what the real risk level will be by the end of the campaign since the 3 months of the analysis period correspond to the drier and most water intensive use months of the hydrologic year. In addition, by looking at the different graphs in Fig. 5, it is possible to appreciate that initial conditions, storage level and hydrologic conditions, play an important role in the final risk level results, although with different effects. None of them has importance for a 12 months anticipation period. Previous hydrologic conditions play an important role in the midterm (Fig. 5b and c) since the most of the streamflow generates in autumn and spring. In the short term (Fig. 5d), the most important aspect is the initial storage level in reservoirs, especially because there is almost no streamflow generation during the summer.

Therefore, according to what we showed in previous paragraphs, a simple scenario definition method for the Orbigo River system could be as following: If the anticipation period is six or less months, the drought scenario will correspond to the scenario in which the average risk level falls by the end of the campaign. Otherwise, if anticipation period is higher than 6 months, the drought scenario will correspond to the scenario above the one in which the average risk level falls by the end of the campaign. This means, if we detect an alert scenario with an anticipation period of 6 months, the measures to activate will be the corresponding to that same scenario in the drought plan. However, if that same alert scenario is the result of a 9 months anticipation period, then the measures to activate will correspond to the pre-alert scenario. Anyway, once we define the drought scenario, we can use the same methodology to assess the risk level with the existing management rules to evaluate the changes introduced by the mitigation measures. In this way, it is possible to select the best measures for each case and their optimal intensity.

\section{Conclusions}

A proper drought preventive system management requires anticipating the possible effects that one episode may have on the system. However, this task reveals to be easy to say but harder to do. First, because of the high degree of uncertainty existing in future hydrological variables prediction. And second, because of the high risk of over reacting if the timing for mitigation measures activation is wrong, generating so-called artificial droughts. On this regard, drought plans supply tools to water managers to effectively handle scarce resources situations and preparing for future events. Anyway, the different operation strategies followed in different water resources systems make that the tools that reveal to be useful for some systems are not that effective in others. 
This paper shows the difficulties of monitoring systems used in current drought plans to properly anticipating drought risk in within-year operated systems due to their high seasonality. The monitoring system currently used does not anticipate the real risk of suffering a severe drought event in many cases. This paper proposes the use of a risk assessment methodology to complement the indicator system so the management of the basin is included in the drought status definition. We show that it is possible to define the current drought scenario by evaluating the possible future status of the system with different anticipation periods. We applied the proposed methodology to the Orbigo River basin, a within-year operated system in the Iberian Peninsula.

The application of the proposed methodology, considering different anticipation times, improves the determination of the current drought scenario including the real management of the basin and not only hydrologic variables normally considered in monitoring systems. Finally, the methodology presented also permits assessing the efficacy of the mitigation measures proposed by calculating new risk levels obtained from their application.

Acknowledgments The authors want to thank the Spanish Ministry of Economy and Competitivity (ComisiónInterministerial de Ciencia y Tecnología, CICYT) for funding the projects INTEGRAME (contract CGL2009-11798), NUTEGES (VI Plan Nacional de I+D+i 2008-2011, CGL2012-34978) and SCARCE (program Consolider-Ingenio 2010, project CSD2009-00065). Also thanks to the European Commission (Directorate-General for Research \& Innovation) for funding the projects DROUGHT-R\&SPI (program FP7ENV-2011, project 282769) and ENHANCE (program FP7-ENV-2012, project 308438). Last but not least to the Confederación Hidrográfica del Duero for providing the data and support to build the models.

Open Access This article is distributed under the terms of the Creative Commons Attribution License which permits any use, distribution, and reproduction in any medium, provided the original author(s) and the source are credited.

\section{References}

Andreu J, Capilla J, Sanchis E (1996) AQUATOOL a generalized decision support system for water resources planning and operational management. J Hydrol 117:269-291

Andreu J, Solera A, Capilla J, Ferrer J (2007) Modelo SIMGES para simulación de cuencas. Manual de usuario v3.00. ISBN 978-84-8363-170-6, Editorial Universidad Politécnica de Valencia, Valencia

Andreu J, Ferrer-Polo J, Mérez MA, Solera A (2009) Decision support system for drought planning and management in the Jucar River Basin, Spain, In 18th World IMACS Congress and MODSIM09 International congress on modelling and simulation. Anderssen RS, Braddock RD and Newham LTH (Edt) ISBN 978-0-9758400-7-8, Modelling and Simulation Society of Australia and New Zealand and International Association for Mathematics and Computers in Simulation, 2377-2383, July 2009

Arrojo Agudo P (2007) Bases para un documento de directrices en material de prevención y gestión de sequías en la planificación hidrológica, In: La sequía en España. Directricesparaminimizarsuimpacto.Cabrera E and BabianoL (Edt.), ISBN 978-84-690-7328-5, Ministry of Environment of Spain, chapter 1, 29-49, 2007

Bordi I, Sutera A (2007) Drought monitoring and forecasting at large scale. In: Rossi G, Vega T, Bonaccorso B (eds) Methods and tools for drought analysis and management, Chapter 1. Springer, Dordrecht, pp 3-27, ISBN 978-1-4020-5923-0

Cancelliere A, Nicolosi V, Rossi G (2009) Assessment of drought risk in water supply systems in coping with Drought risk in agriculture and water supply systems. Adv Nat Technol Haz 26:93-109

EC (2000) Directive 2000/60/EC of theEuropeanParliament and of the Council of 23 October 2000 establishing a frameworkforCommunityaction in thefield of waterpolicy. Official Journal of the European Communities, L327/1

Estrela T, Vargas E (2012) Drought management plans in the European Union. The case of Spain. Water Resour Manag 26:1537-1553 
Hayes MJ, Wilhelmi OV, Knutson CL (2004) Reducing drought risk: bridging theory and practise. Nat Hazards Rev 5:106-113

Mishra AK, Singh VP (2010) A review of drought concepts. J Hydrol 391:202-216

Mishra AK, Singh VP (2011) Drought modeling - a review. J Hydrol 403:157-175

MMA (2007) Plan especial de actuacion en situaciones de alerta y eventual sequia. ConfederacionHidrografica del Duero, Ministerio de MedioAmbiente, Gobierno de España

Preziosi E, Del Bon A, Romano E, Petrangeli AB, Casadei S (2013) Vulnerability to drought of a complex water supply system. The Upper Tiber Basin case study (Central Italy). Water Resour Manag 27:4655-4678

Rossi G, Cancelliere A, Giuliano G (2006) Role of decision support system and multicriteria methods for the assessment of drought mitigation measures. In: Andreu J, Rossi G, Vagliasindi F, Vela A (eds) Drought management and planning for water resources, chapter 9. CRC Press (Taylor \& Francis), Boca Raton, pp 203-240, ISBN 1-56670-672-6

Rossi G, Caporali E, Garrote L (2012) Definition of risk indicators for reservoirs management optimization. Water Resour Manag 26:981-996

Rossi G, Cancelliere A (2013) Managing drought risk in wter supply systems in Europe: a review. Int J Water Resour D 29:272-289

Sánchez-Quispe S (1999) Gestión de Sistemas de Recursos Hídricos con Toma de Decisión Basada en Riesgo. Tesis Doctoral. Universidad Politécnica de Valencia

Sánchez-Quispe S, Andreu J, Solera A (2001) Gestión de Recursos Hídricos con Decisiones Basadas en Estimación del Riesgo. Universidad Politécnica de, Valencia

Tsakiris G, Nalbantis I, Vangelis H, Verbeiren B, Huysmans M, Tychon B, Jacquemin I, Canters F, Vanderhaegen S, Engelen G, Poelmans L, De Becker P, Batelaan O (2013) A system-based paradigm of drought analysis for operational management. Water Resour Manag 27:5281-5297

Wilhite DA (1996) A methodology for drought preparedness. Nat Hazards 13:229-252

Wilhite D, Hayes MJ, Knutson C, Helm Smith K (2000) Plannign for drought: moving from crisis to risk management. J Am Water Resour As 26:697-710 